\title{
The effect of employee behavior on brand personality impressions and brand attitudes
}

\author{
Daniel Wentzel
}

Received: 18 June 2008 / Accepted: 25 February 2009 /Published online: 17 March 2009

(C) Academy of Marketing Science 2009

\begin{abstract}
This research examines how consumers update their brand personality impressions and brand attitudes after interacting with one of the brand's employees. Drawing on stereotyping theory, the author develops a framework that proposes that the impact of an employee's behavior depends on how the employee is categorized. When the employee is considered primarily as an exemplar of the brand's workforce, his or her behavior is generalized more strongly to the brand. When, however, the employee is judged as a relatively unique individual (i.e., when the employee is subtyped), the behavior is not transferred to the brand to the full extent. The results of three studies provide converging evidence and show that the degree to which consumers subtype an employee is determined by the amount of information they possess about the employee, the extent to which they depend on the employee, and their motivation to form an accurate impression. The findings have direct implications for marketers interested in understanding how employees affect the brands they represent.
\end{abstract}

Keywords Brand personality · Brand attitudes ·

Updating processes $\cdot$ Stereotyping theory .

Customer-employee interactions $\cdot$ Self-disclosure

Many researchers have stressed the importance of building a strong brand personality, which refers "to the set of human characteristics associated with a brand" (Aaker 1997 p. 347). Although a number of studies have investigated how consumers form and update their brand personality impressions (Aaker et al. 2004; Johar et al. 2005),

D. Wentzel $(\bowtie)$

Center for Customer Insight, University of St. Gallen,

Rosenbergstr. 51,

9000 St. Gallen, Switzerland

e-mail: daniel.wentzel@unisg.ch systematic work that has examined how employees affect brand personalities has been limited. Yet, Aaker (1997) suggests that "personality traits come to be associated with a brand in a direct way by the people associated with the brand-such as (...) the company's employees" (p. 348). Similarly, Berry (2000) argues that "service performers are a powerful medium for building brand meaning (...). Service providers make or break a brand, for the customers' actual experiences with the service always prevail in defining the brand for them" (p. 135).

As such, the behavior of a frontline employee may be an important driver of consumers' brand personality impressions. For example, imagine a consumer who has made inferences about Harley-Davidson being a rugged brand from such sources as marketing messages and media reports. What would happen if that consumer visited a Harley-Davidson dealership and interacted with a frontline employee who wore a tailor-made suit, offered the consumer a cup of green, organic tea, and generally behaved in a way that was not rugged? To what extent would the consumer update her impressions about the Harley-Davidson brand, and perhaps more interesting, why? How would she update her impressions if the employee's behavior had been more in line with the rugged personality of Harley-Davidson?

Prior research (Aaker et al. 2004; Johar et al. 2005) that has examined the updating of brand personality impressions has mostly focused on non-social information and has not considered the role of employees; that is, the new information that participants were given in these studies did not reflect an employee's behavior. Judgments of social stimuli, however, may differ from judgments of non-social stimuli in important respects (Yoon et al. 2006). For instance, Kardes (1986) demonstrated that the effect of an initial evaluation of a product on subsequent evaluations is 
different from the extent of this effect on the evaluation of people. Hence, one may argue that information based on an employee's behavior has a different effect on consumers' updating processes than information based on a new advertisement. The purpose of this research is to fill the critical gap in marketing research by studying how consumers update their brand impressions after interacting with an employee whose behavior is either consistent or inconsistent with their existing impressions. Drawing on studies from stereotyping theory, I propose that the extent to which consumers update their impressions depends on the amount of information they possess about the employee, the extent to which they depend on the employee, and their motivation to form an accurate impression of the employee. Three studies support these predictions and help further the understanding of how employees affect the brands they represent.

\section{Conceptual development}

To understand how brand impressions may be affected by an employee's behavior, it is useful to draw on stereotyping theory. Stereotypes are "generalized beliefs about groups of people in which all individuals from the group are regarded as having the same set of leading characteristics" (Harré and Lamb 1986, p. 348). Arguably, stereotypes may also be formed at the level of different brands (Matta and Folkes 2005). That is, consumers may develop an expectation about what a "typical" employee of a brand should be like based on advertising or reports in the media (Aggarwal 2004). Hence, stereotypes and brand personalities are similar in that both may cause consumers to develop beliefs about the characteristics of typical group members, which are subsequently used to evaluate an individual belonging to this group.

Research in stereotyping has typically found that the extent to which an individual target affects impressions of the group depends on how the target is categorized (Klein and Snyder 2003; Rothbart and Lewis 1988). When the target is primarily regarded as an exemplar of the group, the behavior is abstracted into a general impression that is transferred to the entire group (Crawford et al. 2002). When, however, the target is considered more strongly as an individual with a unique set of characteristics, (s)he is disassociated from the stereotype. As a result, the behavior is not generalized to the full extent. This process is referred to as "fencing off" or subtyping in the stereotyping literature (Kunda and Oleson 1995; Yzerbyt et al. 1999).

From this perspective, one may argue that consumers would generalize an employee's behavior to a greater extent to the brand when the employee is not subtyped and considered primarily as an exemplar of the brand's workforce. In the following sections, I identify two factors that determine whether consumers engage in subtyping, namely the kind of information that is known about an employee and the degree to which consumers think they are dependent on the employee. Figure 1 summarizes the conceptual model.

Disclosure of pseudorelevant information and behavior generalization

To improve the course of an interaction, frontline employees frequently disclose personal information to customers (Crosby et al. 1990; Price and Arnould 1999). According to social penetration theory (Altman and Taylor 1973), selfdisclosures serve an important symbolic function and communicate "something more than the actual content of what gets exchanged" (Collins and Miller 1994, p. 471). Through disclosing details about the self, an employee signals that (s)he likes a customer and enjoys the interaction they are having. The information that employees disclose on such occasions may often be irrelevant for the final outcome of the interaction and may instead be a reflection of the employee's more general interests, plans, and experiences (Price and Arnould 1999). A frontline employee at an Apple store, for instance, may tell a customer who is looking to buy an iPod that she owns that particular model herself and frequently uses it when she goes biking or running on the weekends. Such information that is irrelevant for the judgment task at hand but is rich and indicative of someone's character is referred to as "pseudorelevant" information (Hilton and Fein 1989).

Research in social psychology suggests that subtyping processes are facilitated by pseudorelevant information. For instance, Kunda and Oleson (1995) exposed participants to a description of a successful, yet introverted lawyer that challenged the stereotype of lawyers as extroverted. As expected, when participants were not given any additional information they changed their stereotypes of lawyers. In contrast, when participants were given a piece of neutral, pseudorelevant information-namely, the size of the firm the lawyer worked for-, they relegated the lawyer to a subtype and did not generalize his behavior. Arguably, disclosing pseudorelevant information in commercial interactions may also lead to subtyping processes.

But why would consumers subtype an employee in the first place? Existing research has argued that subtyping occurs because people are motivated to preserve their stereotypes. As such, subtyping has only been observed when the individual's behavior is inconsistent with the stereotype, allowing people "to maintain their preexisiting global stereotypes even though they are aware that deviants exist" (Kunda and Oleson 1995, p. 565). When, however, the individual's behavior is consistent with the stereotype, 
Fig. 1 Conceptual Model of the Paper.

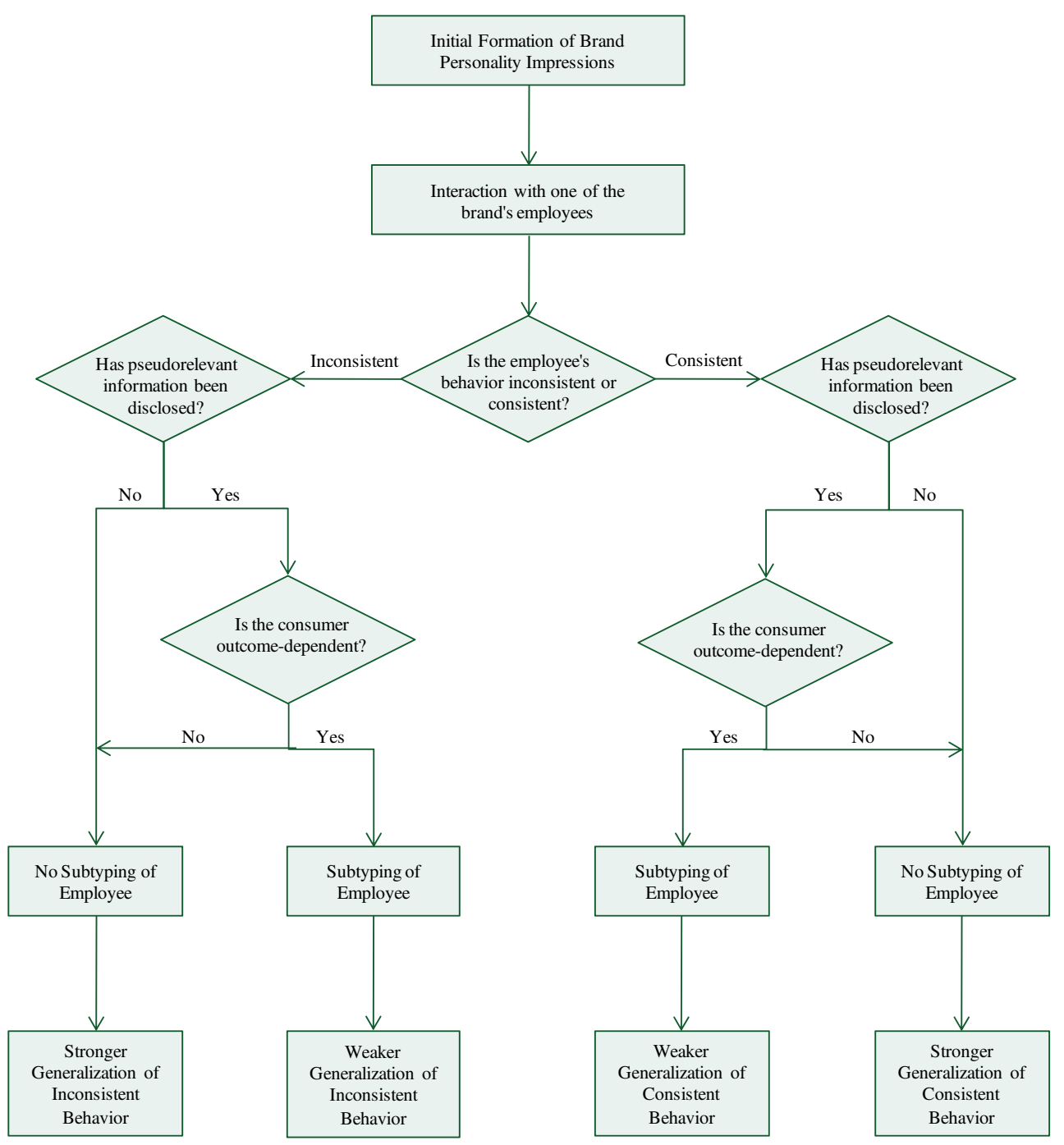

people have little reason to engage in subtyping. Yet, one may question whether this account also applies to interactions between consumers and employees. That is, consumers may not be as motivated to defend their beliefs about a brand's personality as they are to defend their beliefs about social groups.

Instead, it seems more likely that a concern for accuracy may drive consumers to subtype an employee. Regardless of whether the perception is actually correct or not, consumers often perceive that they are dependent on the assistance of an employee for achieving a positive outcome in an interaction (Cowley 2005). Perceivers that are dependent on another person typically disregard the person's category membership and focus more strongly on the person's individuating attributes (Neuberg and Fiske 1987; Ruscher and Fiske 1990). These effects are found because outcome-dependent perceivers have a much greater need to accurately understand and predict their partner's behavior to obtain the desired outcome than perceivers that are not outcome-dependent (Fiske and Neuberg 1990;
Hilton and Darley 1991). Since a person's individuating attributes are usually considered to be a better predictor of his or her behavior than his or her membership in a social category (Kunda and Thagard 1996), outcome-dependent perceivers are more likely to form an impression that is based on their partner's attributes.

Thus, consumers may subtype an employee after receiving pseudorelevant information because they may feel that doing so will help them in gaining a more accurate impression of the employee and not because they are motivated to defend their existing impressions. Extending current theorizing in stereotyping, this line of reasoning implies that subtyping may also occur when the employee's behavior is consistent with consumers' existing impressions.

The extent of subtyping may, in turn, affect the degree of generalization. For example, BMW is generally considered to be a brand with a sophisticated personality. If an employee does not disclose any pseudorelevant information, the consumer is likely to consider the employee primarily as an exemplar of BMW's workforce. In this case, the employee 
should exert a strong impact on brand personality impressions (Klein and Snyder 2003). That is, consumers should update their impressions about BMW's personality in a positive manner if the employee's behavior is sophisticated, whereas they should update their impressions in a negative manner if the behavior is not sophisticated. Brand attitudes should be affected in a similar fashion. Behaviors that are consistent (inconsistent) with existing impressions should exert a positive (negative) impact on brand attitudes (Aaker et al. 2004; Aggarwal 2004).

The extent to which consumers update their brand impressions, however, may be different when an employee discloses pseudorelevant information. For instance, the employee and the consumer may talk about their plans for the upcoming weekend, and the employee may reveal that he plans to go on a hiking trip with his children. In this case, the consumer is likely to subtype the employee and to consider him more strongly as a unique individual than as an exemplar of BMW's workforce. As a result, she should not generalize the employee's behavior as strongly to her perceptions of the brand compared to when she has not received any pseudorelevant information (Klein and Snyder 2003; Rothbart and Lewis 1988). Importantly, the tendency to produce less generalization after receiving pseudorelevant information should be observed when the employee's behavior is consistent as well as when it is inconsistent with existing brand personality impressions. Hence,

H1: Consistent (inconsistent) employee behavior will exert a more positive (a more negative) impact on brand personality impressions and brand attitudes when the employee does not disclose pseudorelevant information compared to when the employee discloses pseudorelevant information.

The moderating influence of outcome dependency

Hypothesis 1 postulates that consumers engage in subtyping because they feel that they are dependent on the employee, which, in turn, increases their motivation to gain an accurate impression. However, one may argue that different interactions are characterized by different degrees of outcome dependency. If this line of reasoning is correct, then a consumer's tendency to subtype an employee on the basis of pseudorelevant details should be more pronounced when the interaction is characterized by a high compared to a low degree of outcome dependency.

Outcome dependency should be higher when a consumer and an employee need to rely on each other's input for producing a successful outcome (Bendapudi and Leone 2003; Bettencourt 1997). For example, a distinctive feature of many commercial exchanges is the possibility of tailoring a product or service to a consumer's exact specifications. That is, in many cases consumers do not buy standardized products or services but are given the chance to customize goods such as furniture, cars, and holidays according to their individual needs. In such cases, consumers need to articulate their needs to an employee and need to rely on the employee to translate those needs into certain features of a good (Bettencourt 1997). Hence, consumers may feel that they depend more strongly on the employee for achieving a successful outcome from the interaction (i.e., a customized wardrobe, car, or holiday).

This perception of dependency should increase the consumer's concern for forming an accurate impression of the employee. Hence, if pseudorelevant information is disclosed, the consumer should subtype the employee and should not transfer the employee's behavior to the full extent to the brand. If such information is not disclosed, the consumer would lack the basis for forming a more individuated impression. Therefore, the availability of pseudorelevant information should determine the extent to which an employee's behavior is generalized to the brand when the interaction is characterized by a high degree of outcome dependency.

Different outcomes are to be expected when outcome dependency is low. For example, a consumer may configure a product by herself at a computer terminal in the store and may therefore believe that it is less important to know what the employee is really like (Neuberg and Fiske 1987). Since forming an impression based on an individual's attributes is more effortful than forming an impression based on an individual's group membership (Gilbert and Hixon 1991), consumers that are not outcome-dependent should not subtype an employee after receiving pseudorelevant information. As a result, they should generalize an employee's consistent or inconsistent behavior to the brand, regardless of the information that is available. Thus,

H2a: Under high outcome dependency, brand personality impressions and brand attitudes will be affected more positively (more negatively) by an employee's consistent (inconsistent) behavior when the employee does not disclose pseudorelevant information compared to when the employee discloses pseudorelevant information.

H2b: Under low outcome dependency, brand personality impressions and brand attitudes will not be affected more positively (more negatively) by an employee's consistent (inconsistent) behavior when the employee does not disclose pseudorelevant information compared to when the employee discloses pseudorelevant information.

Next, the underlying process is investigated. When outcome-dependent consumers are provided with pseudorelevant information, they should subtype the employee and 
consider him or her as a relatively unique individual. As a result, they should produce less generalization. When they are not given any information, they should rate the employee as an anonymous exemplar of the brand's workforce and should generalize the behavior more strongly (Yzerbyt et al. 1999). Hence, judgments of individuality should mediate the relationship between pseudorelevant information and the extent of generalization. Judgments of individuality should, however, not differ as a function of the kind of information that is disclosed when outcome dependency is low. Thus,

H3: Under high outcome dependency, judgments of individuality mediate the relationship between the disclosure of pseudorelevant information and the generalization of an employee's inconsistent or consistent behavior.

STUDY 1: The impact of pseudorelevant information

\section{Design and participants}

The purpose of Study 1 was to test hypothesis 1 . The study used a 2 (employee behavior: inconsistent, consistent) $\times 2$ (pseudorelevant information: present, absent) betweensubjects design. A total of 247 undergraduate students at a Swiss university participated in the study during a mandatory lecture. Participation in the study was voluntary, and participants were entered into a lottery for free movie tickets as an incentive. A fictitious brand called "RoadWay" that sold equipment for off-road motorcycling and mountain biking tours was used in the experiment, and the personality trait that was manipulated was "ruggedness" (Aaker 1997).

\section{Procedure and stimuli}

The study followed the procedure outlined by Johar et al. (2005). To examine how pseudorelevant information affects the generalization of an employee's behavior, it was necessary to induce an initial set of inferences about the brand at the beginning of the study. All participants were thus presented with several brand claims that were pretested to ensure that they evoked ruggedness inferences (e.g., "The brand was set up by two motorcycling fanatics who had been biking around the world for 10 years before they launched the brand."). After reading these brand claims, participants rated the ruggedness of the RoadWay brand ${ }^{1}$

After completing several filler tasks, participants were presented with a role-playing scenario that depicted an

\footnotetext{
${ }^{1}$ All experimental materials for this study and the other studies can be obtained from the author.
}

interaction between a customer and an employee of RoadWay. In the scenarios, a customer went to a RoadWay store to buy a bicycle helmet. The behavior of the employee was either rugged and therefore consistent with the brand personality or not rugged and therefore inconsistent. The consistency of the employee's behavior was manipulated through the activity the employee was engaged in when the customer entered the store, the way he spoke to and dealt with the customer, and his physical look and appearance. For example, in the consistent conditions the employee was repairing a motorcycle when the customer entered the store and wore leather biking boots and pants, whereas in the inconsistent conditions he was watering some plants on his desk and was dressed in a button-down shirt and matching dress pants.

The disclosure of pseudorelevant information was manipulated through a conversation between the customer and the employee at the end of the interaction. In half of the scenarios, the employee did not disclose any pseudorelevant information. In the other half, the employee disclosed a piece of pseudorelevant information, namely that he was a passionate musician and played in a band in his spare time. To avoid confounding effects, the employee was always described as competent, and in all scenarios the customer purchased a bicycle helmet. After participants had finished reading the scenario, they rated the ruggedness of RoadWay a second time. Following this, they indicated their brand attitudes, rated the ruggedness of the employee's behavior and responded to several manipulation checks.

\section{Measures}

Brand personality impressions and brand attitudes Ruggedness ratings were measured both before and after participants were exposed to the scenarios with five ninepoint items (not rugged/rugged, not tough/tough, not outdoorsy/outdoorsy, not masculine/masculine, and not Western/ Western) from Aaker (1997). These items were averaged in both instances $\left(\alpha_{\text {before }}=.76, \alpha_{\text {after }}=.90, \alpha_{\text {dif }}=.74\right)$. Brand attitudes were measured with three seven-point items (bad/ good, unfavorable/favorable, and dislike/like, $\alpha=.92$ ).

Ruggedness of employee To ascertain to what extent the employee's behavior was generalized to the brand, participants rated the ruggedness of the employee's behavior (i.e., How would you describe the employee's behavior during the interaction?) on the same five nine-point items that were used to measure the personality of the brand $(\alpha=.92)$.

Manipulation checks As a manipulation check on the employee's behavior, participants rated on two seven-point items how consistent the behavior had been with RoadWay's personality (inconsistent/consistent, disconfirmed/ 
confirmed the personality, $r=.82$ ). Two checks were necessary to ensure that pseudorelevant information had been manipulated effectively. Firstly, the information that the employee disclosed needed to be rich and indicative of his general character. Therefore, all participants indicated to what extent the employee had disclosed personal, relevant information on two seven-point items (During the interaction, the employee told me about his personal interests; The employee disclosed personal information that was indicative of his general character, $r=.77$ ). Secondly, the information needed to be unrelated to judgments of ruggedness. Hence, all participants indicated to what extent playing in a band is rugged on the same five nine-point items that measured the brand's personality $(\alpha=.85)$.

\section{Results and discussion}

Manipulation checks As expected, a significant main effect revealed that the employee's behavior was rated as being more consistent with the brand's personality in the consistent than in the inconsistent conditions $\left(\mathrm{M}_{\mathrm{cons}}=5.95\right.$, $\left.\mathrm{M}_{\text {incon }}=2.42, F(1,243)=592.30, p<.001\right)$. Furthermore, participants who had received pseudorelevant information felt more strongly that the employee had shared personal, relevant information during the interaction $\left(\mathrm{M}_{\text {info }}=5.29\right.$, $\left.\mathrm{M}_{\text {no_info }}=2.85, F(1,243)=85.47, p<.001\right)$. In addition, all participants believed that knowing that someone plays in a band is irrelevant for judging whether that person is rugged $\left(\mathrm{M}=5.15\right.$ on a nine-point scale, $t(246)_{\text {diff_from_ } 5}=1.45$, $p>.15)$. This judgment did not differ between the conditions $(F(3,243)<1)$. No other treatment effects were significant for both checks.

Brand personality impressions To examine whether brand personality impressions had changed after the scenarios, post-interaction impressions were compared to preinteraction impressions. These comparisons were achieved by calculating the differences between the two sets of measures. Negative values thus indicate a drop in personality impressions, whereas positive values indicate an increase. The results show that brand personality impressions are more strongly affected by the employee's behavior when no pseudorelevant information was disclosed. The four conditions did not differ on initial ruggedness ratings $(F(3,243)<1)$. However, a $2 \times 2$ ANOVA revealed a significant main effect for employee behavior on the difference scores $(F(1,243)=$ $160.81, p<.001)$. More importantly, this main effect was qualified by a behavior $\times$ information interaction $(F(1$, $243)=28.15, p<.001$ ). Following the logic of H1, planned contrasts were performed within the different behavior conditions.
As Fig. 2 shows, inconsistent behavior had a more adverse impact on brand impressions when participants had not received pseudorelevant information compared to when they had received such information $\left(\mathrm{M}_{\mathrm{info}}=-1.25\right.$, $\left.\mathrm{M}_{\text {no_info }}=-2.54, F(1,121)=18.04, p<.001\right)$. A reverse pattern was found when the employee's behavior was consistent. Brand personality impressions were affected more positively when respondents had not been provided with pseudorelevant information $\left(\mathrm{M}_{\mathrm{info}}=.04, \mathrm{M}_{\mathrm{no} \_ \text {info }}=.58, F(1\right.$, 122) $=10.68, p<.002)$.

Brand attitudes The analyses revealed a significant main effect for the consistency of the employee's behavior $(F(1$, $243)=31.69, p<.001)$ and a significant behavior $\times$ information interaction $(F(1,243)=8.30, p<.004)$. As Fig. 2 shows, inconsistent behavior affected brand attitudes more negatively when the employee had not disclosed any information $\left(\mathrm{M}_{\mathrm{info}}=4.66, \mathrm{M}_{\mathrm{no} \text { info }}=4.26, F(1,121)=4.33, p<.04\right)$. Conversely, consistent behavior exerted a more positive impact on brand attitudes when no pseudorelevant details were available $\left(\mathrm{M}_{\text {info }}=5.02, \mathrm{M}_{\text {no_info }}=5.42, F(1,122)=\right.$ $4.41, p<.04)$. Thus, $\mathrm{H} 1$ is also supported for brand attitudes.

Ruggedness of employee If pseudorelevant information indeed leads to subtyping and reduced generalization, then telling participants that the employee was also an amateur musician should not have affected how rugged his behavior was considered to be. In support of this prediction, only a significant main effect for behavior was found $(F(1,243)=$ $229.60, p<.001)$. The main effect for pseudorelevant information $(F(1,243)=1.88, p>.17)$ and the interaction effect were not significant $(F(1,243)<1)$. These results are important since they rule out that the disclosure of pseudorelevant information had an influence on how the employee's behavior was evaluated. That is, an employee who was wearing a button-down shirt and watering plants as the customer entered the store was not rated as more or less rugged if he also told the customer that he played in a band in his spare time $\left(\mathrm{M}_{\text {info }}=4.13, \mathrm{M}_{\text {no_info }}=3.82, F(1\right.$, $121)=1.61, p>.20)$. In a similar vein, an employee who was repairing a motorcycle and wearing biking apparel was not rated as more or less rugged if he disclosed that same information $\left(\mathrm{M}_{\mathrm{info}}=6.59, \mathrm{M}_{\text {no_info }}=6.45, F(1,122)<1\right)$. Hence, these results provide additional support for $\mathrm{H} 1$.

Discussion The results of Study 1 provide support for the notion that pseudorelevant information can affect the extent to which consumers generalize an employee's behavior. However, Study 1 does not give any insights into why consumers may subtype an employee in the first place. Previously, I have argued that consumers may engage in subtyping because they feel they depend on the employee, 
Fig. 2 Study 1: Pseudorelevant Information Interacts with Behavior Consistency to Affect Brand Personality Impressions and Brand Attitudes.
Differences in Personality Impressions

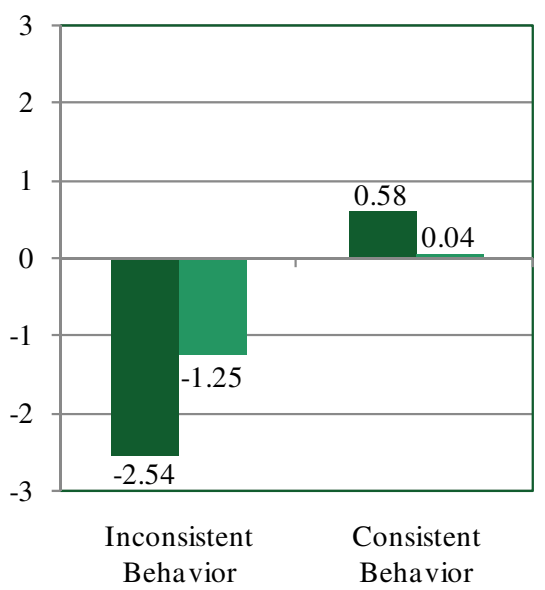

Brand Attitudes

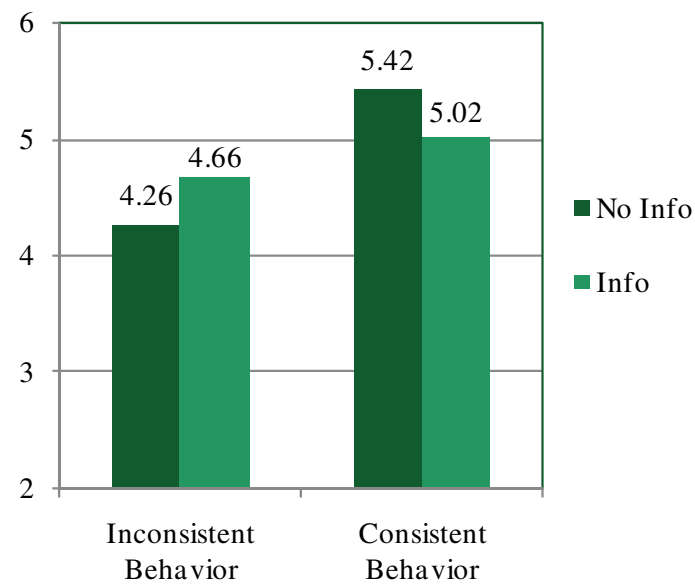

as a result of which they focus on any information that allows them to form a more accurate impression. To provide evidence for this line of reasoning, Study 2 manipulated the degree of outcome dependency in addition to the disclosure of pseudorelevant information. Another purpose of Study 2 was to explore the underlying process.

STUDY 2: The impact of pseudorelevant information and outcome dependency

\section{Design and participants}

The purpose of Study 2 was to test hypotheses $2 a, 2 b$, and 3. The study used a 2 (employee behavior: inconsistent, consistent) $\times 2$ (pseudorelevant information: present, absent) $\times 2$ (outcome dependency: low, high $) \times 2$ (order of evaluation: brand first, employee first) betweensubjects design. A total of 209 undergraduate students at a Swiss university participated in the study during a mandatory lecture. As an incentive, participants were entered into a lottery for Amazon gift vouchers. To increase the generalizability of the results, Study 2 focused on a different product category (i.e., a furniture brand called "Hansen Design" specializing in upscale furniture) and a different brand personality trait (i.e., "sophistication", Aaker 1997).

\section{Procedure and stimuli}

The procedure in Study 2 was slightly different than in the first study. In Study 1, participants were exposed to a number of brand claims to induce an initial set of personality impressions. In Study 2, these claims were inserted into an ad in order to achieve greater realism. Hence, participants were first exposed to an ad that contained several pictures and that described Hansen Design as a brand with a sophisticated personality (e.g., "Since starting our business, we have been awarded over thirty times at international design competitions"). After looking at this ad, participants rated to what extent Hansen Design was a sophisticated brand.

After completing several filler tasks, participants were presented with a role-playing scenario describing an interaction between a customer and an employee at a Hansen Design store. In the scenarios, a customer went to a Hansen Design store to buy a new wardrobe. The extent to which the employee's behavior was consistent with the personality of the brand was manipulated similarly as in Study 1. For instance, in the consistent (inconsistent) conditions, the employee was drinking a latte macchiato (a chocolate milk) when the customer entered the store, was dressed in an elegant, dark suit (was dressed in an ill-fitting corduroy suit), and used words and phrases that were eloquent (colloquial).

Outcome dependency was manipulated by varying the extent to which participants needed the assistance of the employee to complete a successful purchase. In all conditions, the employee told the customer that Hansen Design had a new software that allowed one to customize one's own wardrobe. In the low-dependency conditions, the customer asked the employee to show her (him) how the software worked and customized a wardrobe by herself (himself) at a computer terminal. In the high-dependency conditions, the customer asked the employee to take him (her) through the process and both needed to work together in order to customize a wardrobe. Hence, in these conditions the customer depended more strongly on the assistance of the employee for achieving a successful outcome (i.e., a tailored wardrobe).

The manipulation of pseudorelevant information followed the procedure of Study 1. At the end of the 
interaction, the employee and the customer talked about their plans for the upcoming weekend. In half of the conditions, the employee disclosed that he coached a junior hockey team in his spare time and that he would accompany his team to a competition on the weekend. As in Study 1, the employee was always described as competent, and in all scenarios the customer ended up buying a wardrobe. After reading the scenarios, participants responded to the dependent measures. In Study 1, participants first rated the brand and then rated the employee on the same attributes. To ensure that the results would not be affected by this particular order, the order of evaluation (i.e., brand first, employee first) was counterbalanced in Study 2. After rating the brand and the employee, participants responded to the other measures.

\section{Measures}

Brand personality impressions and brand attitudes Sophistication ratings were measured before and after the scenarios with four nine-point items (not upper class/upper class, not good looking/good looking, not charming/ charming, not glamorous/glamorous) adopted from Aaker (1997). Scale reliability was satisfactory in all instances $\left(\alpha_{\text {before }}=.81, \alpha_{\text {after }}=.89, \alpha_{\text {dif }}=.73\right)$. Brand attitudes were measured with the same items as in Study $1(\alpha=.88)$.

Sophistication of employee Participants rated the sophistication of the employee on the same four nine-point items that measured the personality of Hansen Design $(\alpha=.93)$.

Individuality judgments Finally, participants also rated to what extent they considered the employee to be a relatively unique individual on three seven-point items (When I think of the employee, I see a person with a unique set of characteristics; I have a good idea about who and how the employee really is; I would think of the employee as a unique individual rather than as an anonymous salesperson, $\alpha=.84$ ).

Manipulation checks The manipulation checks for the consistency of the employee's behavior $(r=.93)$ and for pseudorelevant information were the same as in Study 1 $(r=.82)$. In addition, participants rated to what extent coaching a hockey team was a sophisticated activity on the same four nine-point items that measured the sophistication of the brand $(\alpha=80)$. As a check on outcome dependency, participants indicated on two seven-point items how strongly they had depended on the employee (The employee helped me a lot in customizing a wardrobe that corresponded to my needs; While selecting my wardrobe, I relied strongly on the assistance of the employee, $r=.59$ ).

\section{Results and discussion}

The analyses showed no effects for the order of evaluation, so the data were collapsed across the two different order conditions.

Manipulation checks As expected, the employee's behavior was rated as being more consistent with the brand's personality in the consistent than in the inconsistent conditions $\left(\mathrm{M}_{\text {cons }}=5.62, \mathrm{M}_{\text {incons }}=2.35, F(1,201)=313.05\right.$, $p<.001)$. Also, participants that had been told that the employee coached a junior hockey team felt more strongly that the employee had disclosed personal information $\left(\mathrm{M}_{\text {info }}=5.70, \mathrm{M}_{\text {no_info }}=2.91, F(1,201)=190.26, p<.001\right)$. Importantly, all participants agreed that knowing that someone coaches a hockey team is irrelevant for judging whether that person is sophisticated $(\mathrm{M}=4.89$ on a nine-point scale, $\left.t(208)_{\text {diff_from_5 } 5}=-1.15, p>.25\right)$. This judgment did not differ between the different conditions $(F(7,201)<1)$. Finally, participants in the high dependency conditions reported that they had relied more strongly on the employee than those in the low dependency conditions $\left(\mathrm{M}_{\text {high_dep }}=\right.$ $\left.5.26, \mathrm{M}_{\text {low_dep }}=2.85, F(1,201)=269.41, p<.001\right)$. No other treatment effects were significant.

Brand personality impressions A $2 \times 2 \times 2$ ANOVA revealed the predicted three-way interaction on the difference scores $(F(1,201)=9.94, p<.002)$, providing initial support for $\mathrm{H} 2 \mathrm{a}$ and $\mathrm{H} 2 \mathrm{~b}$. Separate analyses were subsequently conducted within the inconsistent and consistent behavior conditions. The four inconsistent conditions did not differ on initial sophistication ratings $(F(3,101)<1)$. However, a $2 \times 2$ ANOVA on the difference scores produced a significant main effect for dependency $(F(1,101)=5.70, p<.02)$ and a significant information $\times$ dependency interaction $(F(1$, $101)=4.83, p<.03)$. As Fig. 3 shows, outcome dependency moderated the impact of pseudorelevant information. Under high dependency, the employee's behavior had a more adverse impact on brand personality impressions when participants had not received pseudorelevant information compared to when they had received such information $\left(\mathrm{M}_{\text {info }}=-.85, \mathrm{M}_{\text {no_info }}=-1.75, F(1,46)=\right.$ $6.05, p<.02)$. Under low dependency, however, pseudorelevant information did not have an effect on personality impressions. Participants did not form different impressions about the brand when they had been (relative to when they had not been) provided with such information $\left(\mathrm{M}_{\text {info }}=-2.03 ; \mathrm{M}_{\text {no info }}=-1.80, F(1,55)<1\right)$.

Analogous results were obtained for the consistent conditions (see Fig. 4). Again, initial personality ratings did not differ between the four conditions $(F(3,100)<1)$. A $2 \times 2$ ANOVA only yielded a significant interaction effect $(F$ $(1,100)=5.41, p<.03)$. Under high outcome dependency, 
Fig. 3 Study 2: Pseudorelevant Information Interacts with Outcome Dependency to Affect Brand Personality Impressions and Brand Attitudes (Inconsistent Behavior Conditions).

\section{Differences in Personality Impressions}

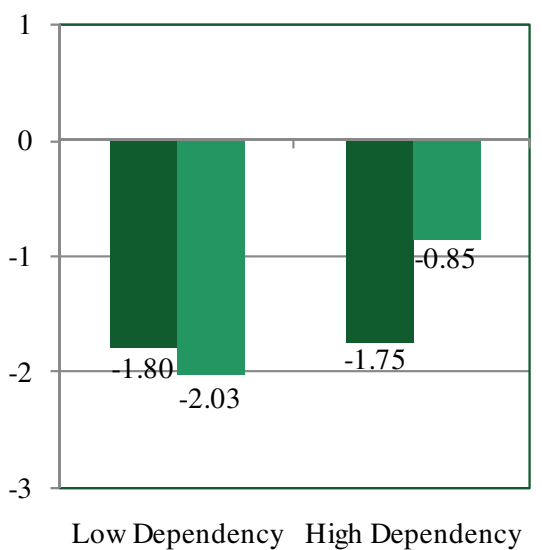

Brand Attitudes

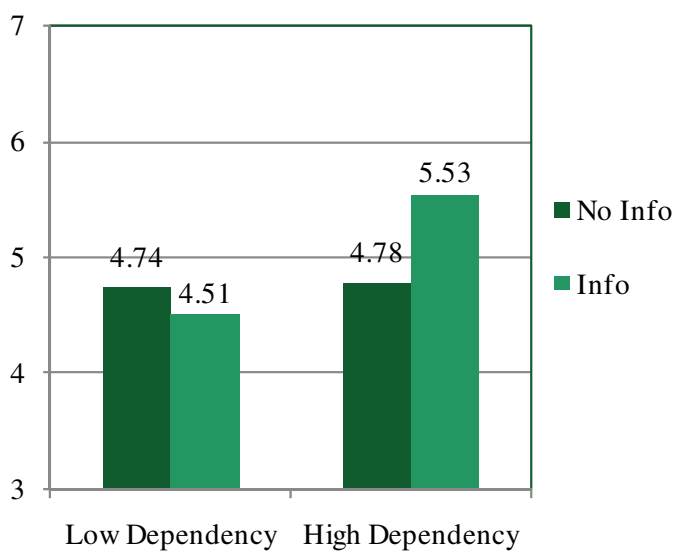

participants formed more positive brand personality impressions when the employee had not disclosed any information $\left(\mathrm{M}_{\text {info }}=-.12 ; \mathrm{M}_{\text {no_info }}=.58, F(1,52)=7.39\right.$, $p<.001)$. On the other hand, when they were not outcomedependent, their brand personality impressions did not differ as a function of the kind of information they had received $\left(\mathrm{M}_{\text {info }}=.63 ; \mathrm{M}_{\text {no_info }}=.44, F(1,48)<1\right)$. Hence, $\mathrm{H} 2$ and $\mathrm{H} 2 \mathrm{~b}$ are supported for consistent as well as inconsistent behaviors.

Brand attitudes $\mathrm{H} 2 \mathrm{a}$ and $\mathrm{H} 2 \mathrm{~b}$ were also confirmed for brand attitudes. A $2 \times 2 \times 2$ ANOVA showed the hypothesized three-way interaction $(F(1,201)=7.94, p<.005)$. Separate analyses were subsequently performed within the different behavior conditions. A $2 \times 2$ ANOVA for the inconsistent conditions revealed a significant main effect for dependency $(F(1,101)=4.66, p<.04)$ and a significant information $\times$ dependency interaction $(F(1,101)=4.04$, $p<.05$, see Fig. 3). Under high dependency, brand attitudes were more negative when no pseudorelevant information had been disclosed $\left(\mathrm{M}_{\text {info }}=5.53, \mathrm{M}_{\text {no_info }}=4.78, F(1,46)=\right.$
$5.98, p<.02)$. Under low dependency, however, the kind of information that had been disclosed did not affect brand attitudes $\left(\mathrm{M}_{\text {info }}=4.51, \mathrm{M}_{\text {no_info }}=4.74, F(1,55)<1\right)$.

Analogous results were obtained for the consistent conditions. Again, only the information $\times$ dependency interaction was significant $(F(1,100)=4.08, p<.05$, see Fig. 4). When outcome dependency was high, participants exhibited more positive brand attitudes if they had not received any information $\left(\mathrm{M}_{\mathrm{info}}=4.95, \mathrm{M}_{\mathrm{no} \_ \text {info }}=5.62, F(1\right.$, $52)=4.73, p<.04)$. When outcome dependency was low, however, the availability of pseudorelevant information had no effect on brand attitudes $\left(\mathrm{M}_{\mathrm{info}}=5.58, \mathrm{M}_{\mathrm{no} \_ \text {info }}=5.51\right.$, $F(1,48)<1)$.

Sophistication of employee A $2 \times 2 \times 2$ ANOVA on the perceived sophistication of the employee's behavior only yielded a significant main effect for behavior $(F(1,201)=$ $350.34, p<.001)$. That is, the employee was considered as more sophisticated in the consistent $(\mathrm{M}=6.58)$ than in the inconsistent conditions $(\mathrm{M}=3.08)$. All other main or interaction effects did not approach significance. These
Fig. 4 Study 2: Pseudorelevant Information Interacts with Outcome Dependency to Affect Brand Personality Impressions and Brand Attitudes (Consistent Behavior Conditions).
Differences in Personality Impressions

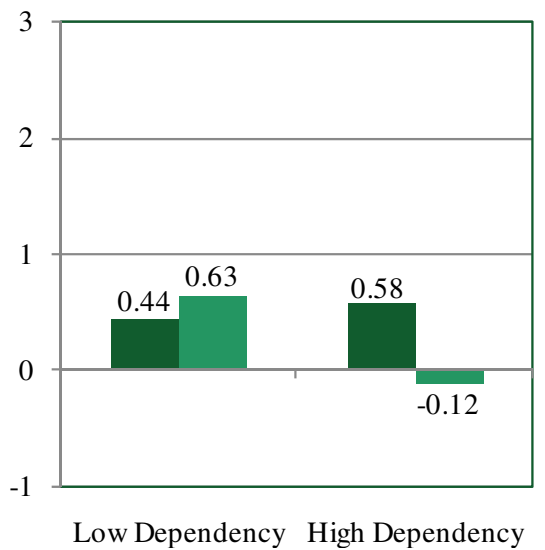

\section{Brand Attitudes}

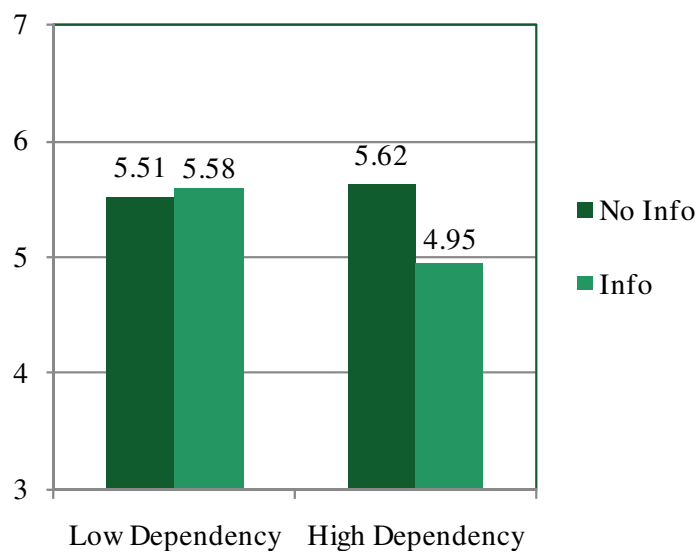


results suggest that the disclosure of pseudorelevant information and the degree of dependency did not affect the evaluation of the employee's behavior; however, these variables determined to what the extent the behavior was generalized to the brand.

Individuality judgments A $2 \times 2 \times 2$ ANOVA on individuality judgments revealed significant main effects for behavior $(F(1,201)=19.18, p<.001)$, information $(F(1,201)=5.56$, $p<.02)$, as well as an information $\times$ dependency interaction $(F(1,201)=8.22, p<.005)$.

A $2 \times 2$ ANOVA for the inconsistent conditions only yielded a significant information $\times$ dependency interaction $(F$ $(1,101)=4.24, p<.04)$. Outcome-dependent participants considered the employee more strongly as a unique individual when they had received pseudorelevant information $\left(\mathrm{M}_{\text {info }}=4.98, \mathrm{M}_{\text {no } \_ \text {info }}=4.13, F(1,46)=7.08, p<.02\right)$. As expected, the kind of information that participants had received had no effect on these judgments when dependency was low $\left(\mathrm{M}_{\text {info }}=4.18 ; \mathrm{M}_{\text {no _info }}=4.31, F(1,55)<1\right)$. Similar results were revealed in the consistent conditions. Again, there was a significant information $\times$ dependency interaction $(F(1,100)=4.04, p<.05)$. Specific contrasts showed that individuality judgments differed as a function of the kind of information that had been disclosed when dependency was high $\left(\mathrm{M}_{\text {info }}=4.32, \mathrm{M}_{\text {no_info }}=3.23, F(1\right.$, $52)=7.76, p<.01)$. When dependency was low, there were no differences in individuality judgments $\left(\mathrm{M}_{\mathrm{info}}=3.36\right.$, $\left.\mathrm{M}_{\text {no_info }}=3.42, F(1,48)<1\right)$.

Next, I examined if individuality judgments mediated the impact of pseudorelevant information under high-dependency conditions, following the recommendations from Baron and Kenny (1986). Note that it was necessary to perform separate analyses for the two behavior conditions since the relationship between pseudorelevant information and brand impressions should be positive in the inconsistent and negative in the consistent conditions. Firstly, pseudorelevant information (dummy variable: absent $=0$, present $=1$ ) had an impact on the dependent variables (Inconsistent: $\beta_{\text {diff }}=.34, p<$ $.02 ; \beta_{\mathrm{att}}=.33, p<.03$; Consistent: $\beta_{\mathrm{diff}}=-.35, p<.001$; $\left.\beta_{\text {att }}=-.29, p<.04\right)$. Secondly, pseudorelevant information was also related to individuality judgments (Inconsistent: $\beta=.37, p<.02$; Consistent: $\beta=.36, p<.01$ ). Thirdly, individuality judgments were a significant predictor of the dependent variables (Inconsistent: $\beta_{\text {diff }}=.59, p<.001 ; \beta_{\text {att }}=.50$, $p<.001 ;$ Consistent: $\beta_{\mathrm{diff}}=-.44, p<.001 ; \beta_{\mathrm{att}}=-.47$, $p<.001)$. Lastly, when both pseudorelevant information and individuality judgments were included in the regression model, the mediator remained a significant predictor (Inconsistent: $\beta_{\text {diff }}=.54, p<.001 ; \beta_{\mathrm{att}}=.43, p<.003$; Consistent: $\left.\beta_{\text {diff }}=-.36, p<.01 ; \beta_{\text {att }}=-.42, p<.002\right)$, whereas the impact of the independent variable was eliminated (Inconsistent: $\beta_{\text {diff }}=.14, p>.27$, Sobel: $z=2.26, p<.03 ; \beta_{\mathrm{att}}=.18, p>.19$,
Sobel: $z=2.03, p<.05$; Consistent: $\beta_{\text {diff }}=-.22, p>.10$, Sobel: $z=-1.99, p<.05 ; \beta_{\mathrm{att}}=-.14, p>.29$, Sobel: $z=-2.10, p<.04$ ). Thus, H3 is confirmed.

Discussion Study 2 shows that outcome dependency moderates the effect of pseudorelevant information on the generalization of an employee's behavior. Dependent participants subtyped the employee once they had received pseudorelevant information. As a consequence, they generalized his behavior to a lesser extent to the brand relative to participants that had not been given any information. On the other hand, regardless of the information that they had received, participants that were not outcome-dependent did not make different judgments about the brand and the employee. These results support the general model previously proposed. That is, dependency heightens a consumer's concern for accuracy, which, in turn, may lead her to subtype an employee after receiving pseudorelevant information.

However, there may also be a competing explanation for these findings that is not based on accuracy-motivated subtyping. Arguably, the results may have been influenced by a self-serving attributional bias (e.g., Sedikides et al. 1998). Bendapudi and Leone (2003) found that consumers that participate in the production of a good are more likely to attribute positive outcomes to themselves than to the firm. In a similar vein, participants in the high-dependency conditions may have been motivated to attribute the positive, jointly produced outcome (i.e., the customized wardrobe) more strongly to themselves than to the employee. To achieve this, they may have looked for information that would allow them to disassociate the employee from the entire experience, regardless of the employee's particular behavior.

Although this explanation seems somewhat less plausible, it seemed important to gather more evidence for the underlying process. One possibility to address this issue consists in manipulating accuracy motivation directly and keeping the degree of dependency constant across all conditions. In this case, manipulating accuracy motivation should lead to a similar pattern of results as manipulating outcome dependency. That is, accuracy-motivated consumers should (should not) subtype the employee if they have (have not) received pseudorelevant information. Therefore, pseudorelevant information should determine the extent to which the employee's behavior is generalized to the brand. Different outcomes are to be expected when accuracy motivation is low. Consumers that are not accuracymotivated are less likely to focus on pseudorelevant information. Hence, these consumers should form very similar impressions about the brand, regardless of the amount of information they have received.

This proposition was tested in Study 3. If this proposition is confirmed, this would lend further support to my 
conceptual model, suggesting that accuracy concerns are the underlying determinant for the formation of subtypes. At the same time, an explanation based on self-serving biases would be rendered much less plausible. That is, this account may not fully explain why consumers would only exhibit a self-serving bias (and thus produce less generalization) when their accuracy concerns are high, but not when they are low.

Since Studies 1 and 2 showed that the effects of pseudorelevant information are similar for inconsistent as well as consistent behaviors, I limited my analysis to inconsistent behaviors. That is, only hypotheses for these kinds of behaviors are forwarded.

H4a: Under high accuracy motivation, brand personality impressions and brand attitudes will be affected more negatively by an employee's inconsistent behavior when the employee does not disclose pseudorelevant information compared to when the employee discloses pseudorelevant information.

H4b: Under low accuracy motivation, brand personality impressions and brand attitudes will not be affected more negatively by an employee's inconsistent behavior when the employee does not disclose pseudorelevant information compared to when the employee discloses pseudorelevant information.

Finally, accuracy motivation should elicit similar cognitive processes as outcome dependency. When accuracy motivation is high, pseudorelevant information should lead to higher judgments of individuality, which, in turn, should mediate the impact of the employee's behavior on personality impressions and attitudes. When accuracy motivation is low, the extent to which pseudorelevant information is disclosed should not affect judgments of individuality. Hence,

H5: Under high accuracy motivation, judgments of individuality mediate the relationship between the disclosure of pseudorelevant information and the generalization of an employee's inconsistent behavior.

STUDY 3: The impact of pseudorelevant information and accuracy motivation

\section{Design and participants}

Study 3 used a 2 (pseudorelevant information: present, absent) $\times 2$ (accuracy motivation: low, high) betweensubjects design. Eighty-nine graduate students at a Swiss university participated in the study. A travel agency specializing in adventure travels called "Savannah Tours" was used, and the personality trait that was manipulated was "excitement" (Aaker 1997). Study 3 relied on short films instead of role-playing scenarios to portray an interaction at a branch of Savannah Tours. Although scenarios are widely used in consumer research, they are criticized for lacking the richness that characterizes real interactions. Therefore, researchers have argued that filmed stimuli shown in a laboratory can convey the richness of real interactions, while still providing control over the independent variables (Grandey et al. 2005).

\section{Procedure and stimuli}

The procedure was similar as in Study 2. At first, participants were exposed to an ad that described "Savannah Tours" as a brand with an exciting personality (e.g., "In most cases, our trips go through remote territories where no or very few people have settled."). After reading this information, they indicated to what extent they thought "Savannah Tours" was an exciting brand.

After completing several filler tasks, participants received a booklet that contained the manipulation of accuracy motivation. Consistent with prior research, accuracy motivation was manipulated through different sets of instructions (Thompson et al. 1994). Participants in the high-accuracy conditions were instructed to form as accurate an impression as possible about the employee. To increase the relevance of this task, they were told that being able to form accurate impressions is an important skill and often determines whether one's interactions in daily life are successful. In contrast, participants in the low-accuracy conditions received instructions designed to undermine the importance of forming an accurate impression.

After participants had finished reading the instructions, they watched one of two films showing an interaction between a customer and an employee of Savannah Tours. The employee was portrayed by a trained actress who had extensive experience in being on-stage. All scenes were shot from the same perspective and showed the employee sitting at a desk, with her upper body and face in the middle of the screen. To minimize the influence of the customer, only the customer's back was in view and the script of the customer was kept to a minimum.

Both films consist of two different scenes, with the first scene being the same in both conditions. In the first scene, the customer enters the office and expresses his interest in booking a trip to Canada. Following this, the employee checks her computer to see which trips are available in the specified time period, explains the itinerary of the trip, and answers some questions from the customer. The second scene depicts the end of the interaction and manipulates the disclosure of pseudorelevant information. In half of the conditions, the customer thanks the employee for her help and leaves the office. In the other half, a short conversation ensues before the customer leaves, during which the 
employee discloses that she is an amateur clarinet player. As already mentioned, the employee's behavior was not manipulated and was always inconsistent with the brand personality (i.e., unexciting). For instance, when the customer enters the office, the employee is working on some balance sheets and tells the customer that she is preparing the annual statement of Savannah Tours. Furthermore, the employee is dressed in a black business costume and speaks in a polite, albeit formal manner. After watching the films, participants rated the excitement of Savannah Tours a second time and responded to the other dependent measures.

\section{Measures}

Brand personality impressions and brand attitudes Excitement ratings were measured both before and after participants were exposed to the films on four nine-point items (not exciting/exciting, not spirited/spirited, not imaginative/ imaginative, not unique/unique) adapted from Aaker (1997). Scale reliability was satisfactory in all instances $\left(\alpha_{\text {before }}=.81, \alpha_{\text {after }}=.92, \alpha_{\text {dif }}=.77\right)$. Brand attitudes were measured with the same items as in Study 1 and $2(\alpha=.93)$.

Excitement of employee The extent to which the employee's behavior was exciting was measured on the same four items that measured the personality of the brand $(\alpha=.84)$.

Individuality judgments Participants rated to what extent they thought the employee was a unique individual on the same three items as in Study $2(\alpha=.80)$.

Manipulation checks The manipulation checks for the consistency of the employee's behavior $(r=.84)$ and for pseudorelevant information were the same as in Study 1 $(r=.81)$. Furthermore, participants rated to what extent playing the clarinet was exciting on the same four items that measured the excitement of the brand $(\alpha=.84)$. As a check on accuracy motivation, participants rated on two seven-point items how motivated they had been to form an accurate impression (I was very motivated to form an accurate impression of the employee; I tried very hard to get a good idea of the employee's character, $r=.72$ ).

\section{Results and discussion}

Manipulation checks Participants considered the employee's behavior to be inconsistent with the personality of Savannah Tours $(\mathrm{M}=2.42$ on a seven-point scale, $\left.t(88)_{\text {diff_from } \_4}=-12.51, p<.001\right)$. Importantly, this judgment did not differ between the different conditions $(F(3$, $85)<1$ ). Furthermore, participants that had been told that the employee played the clarinet felt more strongly that the employee had shared personal information during the interaction $\left(\mathrm{M}_{\text {info }}=5.64, \mathrm{M}_{\text {no_info }}=2.71, F(1,85)=73.09\right.$, $p<.001)$. More importantly, all participants believed that knowing that someone plays the clarinet is irrelevant for judging whether that person is exciting $(\mathrm{M}=4.68$ on a seven-point scale, $\left.t(88)_{\text {diff_from_4 }}=-1.38, p>.17\right)$. This judgment did not differ between the four conditions $(F(3,85)=1.33, p>.27)$. Finally, the motivation check showed that high-accuracy participants were more motivated to form an accurate impression of the employee than low-accuracy participants $\left(\mathrm{M}_{\text {high_mot }}=4.42, \mathrm{M}_{\text {low_mot }}=\right.$ $3.13, F(1,85)=18.41, p<.001)$. No other treatment effects were significant for all checks.

Brand personality impressions Initial excitement ratings did not differ between the conditions $(F(3,85)<1)$. As expected, a $2 \times 2$ ANOVA on the difference scores only revealed a significant information $\times$ motivation interaction $(F(1,85)=4.68, p<.04)$. Specific contrasts were subsequently performed within the two motivation conditions. As Fig. 5 shows, pseudorelevant information affected brand personality impressions when participants were accuracymotivated. Brand personality impressions were more positive when the employee had disclosed that she was a clarinet player compared to when she had not disclosed this information $\left(\mathrm{M}_{\text {info }}=-1.56, \mathrm{M}_{\text {no_info }}=-2.86, F(1,44)=7.53\right.$, $p<.001)$. When participants were not accuracy-motivated, however, pseudorelevant information had no effect on brand personality impressions $\left(\mathrm{M}_{\text {info }}=-2.67, \mathrm{M}_{\text {no_info }}=-2.54, F(1\right.$, $41)<1)$. Hence, $\mathrm{H} 4 \mathrm{a}$ and $\mathrm{H} 4 \mathrm{~b}$ were confirmed.

Brand attitudes $\mathrm{H} 4 \mathrm{a}$ and $\mathrm{H} 4 \mathrm{~b}$ were also confirmed for brand attitudes. A $2 \times 2$ ANOVA showed a significant main effect for motivation $(F(3,85)=5.21, p<.03)$ and a significant information $\times$ motivation interaction $(F(1,85)=4.73, p<.04)$. When accuracy motivation was high, participants exhibited more positive attitudes when they had received pseudorelevant information $\left(\mathrm{M}_{\text {info }}=4.72, \mathrm{M}_{\text {no_info }}=3.75, F(1,44)=\right.$ $7.20, p<.01)$. When accuracy motivation was low, the availability of pseudorelevant information had no effect on brand attitudes $\left(\mathrm{M}_{\mathrm{info}}=3.51, \mathrm{M}_{\text {no_info }}=3.72, F(1,41)<1\right)$.

Excitement of employee behavior A $2 \times 2$ ANOVA for the employee's behavior revealed that the main effect for pseudorelevant information $(F(1,85)<1)$, the main effect for motivation $(F(1,85)<1)$, and the interaction effect $(F(1,85)<1)$ were insignificant, suggesting that the employee was perceived as equally unexciting across all conditions.

Individuality judgments A $2 \times 2$ ANOVA only yielded a significant information $\times$ motivation interaction $(F(1,85)=$ 
Fig. 5 Study 3: Pseudorelevant Information Interacts with Accuracy Motivation to Affect Brand Personality Impressions and Brand Attitudes (Inconsistent Behavior).
Differences in Personality Impressions

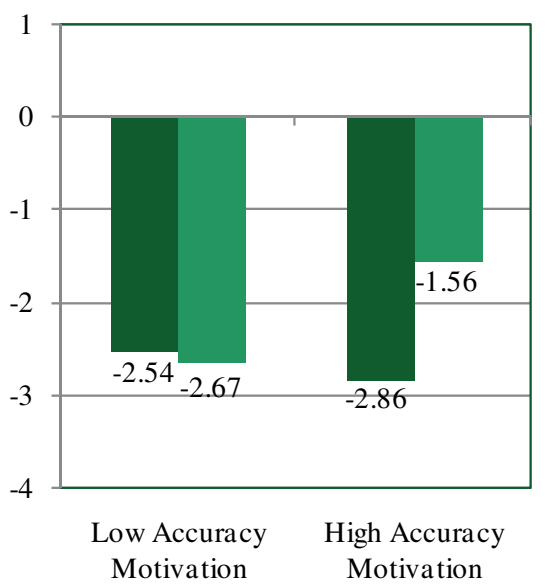

Brand Attitudes

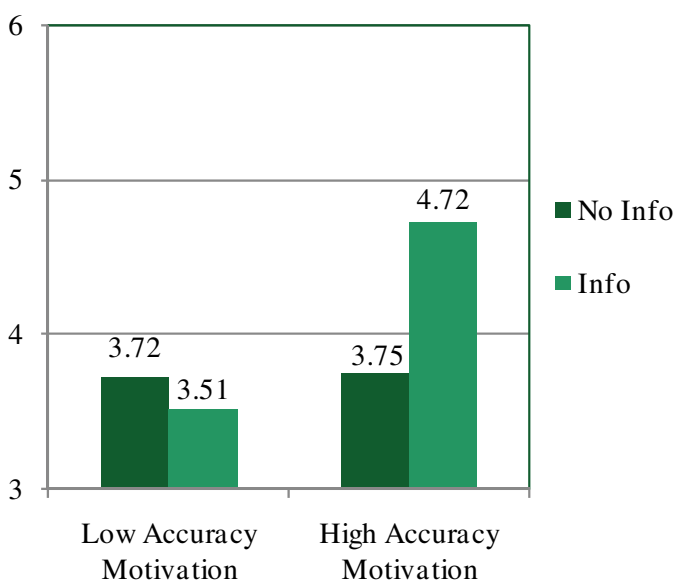

4.51, $p<.04)$. Participants that were accuracy-motivated rated the employee more strongly as an individual when the employee had disclosed pseudorelevant information $\left(\mathrm{M}_{\text {info }}=4.07, \mathrm{M}_{\text {no_info }}=3.13, F(1,44)=5.74, p<.02\right)$. As expected, the disclosure of information had no effect on individuality judgments when participants were not accuracymotivated $\left(\mathrm{M}_{\mathrm{info}}=3.18, \mathrm{M}_{\text {no info }}=3.30, F(1,41)<1\right)$.

As in Study 2, I examined if individuality judgments mediated the impact of pseudorelevant information under high-accuracy conditions. Firstly, pseudorelevant information had a significant impact on the dependent variables ( $\left.\beta_{\text {diff }}=.38, p<.009 ; \beta_{\text {att }}=.36, p<.01\right)$. Secondly, pseudorelevant information was also related to individuality judgments $(\beta=.34, p<.03)$. Thirdly, individuality judgments were a significant predictor of the dependent variables ( $\left.\beta_{\text {diff }}=.60, p<.001, \beta_{\text {att }}=.56, p<.001\right)$. Lastly, when both pseudorelevant information and individuality judgments were included in the model, the mediator remained a significant predictor $\left(\beta_{\mathrm{diff}}=.53, p<.001 ; \beta_{\mathrm{att}}=.49, p<.01\right)$, whereas the impact of the independent variable was eliminated $\left(\beta_{\mathrm{diff}}=.20, p>.12\right.$, Sobel: $z=2.08, p<.04$; $\beta_{\text {att }}=.23, p>.10$, Sobel: $\left.z=2.01, p<.05\right)$. Thus, H5 and the postulated mediation process are confirmed.

Discussion Study 3 was designed to examine how accuracy motivation affects the generalization of an employee's behavior. When accuracy motivation was high, participants subtyped the employee after receiving pseudorelevant information, replicating the results from the first two studies. This effect did not materialize, however, when accuracy motivation was low. In this respect, Study 3 increases the plausibility of my general model, confirming that consumers may subtype employees because of underlying accuracy concerns.

\section{General discussion}

The objective of this research was to determine how consumers update their brand personality impressions and brand attitudes after interacting with an employee whose behavior is either inconsistent or consistent with their existing impressions. The data supported my basic premise that the extent to which an employee's behavior is generalized to the brand depends on the extent to which the employee is subtyped. The findings were robust across different personality traits (ruggedness, sophistication, and excitement) and decision contexts (biking equipment, furniture, and adventure travels). Study 1 showed that participants that had been provided with pseudorelevant information subtyped the employee, as a result of which they did not generalize his behavior to the full extent to the brand. Study 2 extended these findings to demonstrate that the effects were more pronounced when participants depended on the employee for achieving a successful outcome. Finally, Study 3 showed that participants engaged in subtyping because they desired to gain an accurate impression of the employee.

This research makes several contributions to the literature. Firstly, the studies contribute to research on the formation and updating of brand personality impressions (Aaker et al. 2004; Johar et al. 2005). Earlier studies have suggested that "personality traits come to be associated with a brand in a direct way by the people associated with the brand - such as (...) the company's employees" (Aaker 1997, p. 348). My studies suggest that this association is more complex than previously envisioned. Without knowing if consumers consider an employee as an exemplar of the brand's workforce or as a relatively unique individual, it may be impossible to predict how brand personality impressions are affected by the employee's behavior. As 
such, "branding tools" based on social cues, such as an employee's behavior in a customer interaction, may differ in important respects from branding tools based on non-social cues, such as advertising messages. Non-social cues may be used in a straightforward manner to update one's impressions; that is, consumers may infer trait-relevant meaning from a new ad campaign and may transfer that meaning directly to their existing personality impressions (Johar et al. 2005). Social cues, such as an employee's behavior, may require a different form of inferencing. That is, before being able to generalize the meaning of an employee's behavior, consumers may first need to decide how to categorize the employee. Hence, the current research adds to the literature on brand personality by showing that social cues may be processed differently than non-social cues.

Secondly, this research also adds to the stereotyping literature. Whereas previous research has only observed subtyping processes when the target's behavior was inconsistent with the stereotype, this study has found that consumers may subtype an employee even when the employee's behavior is consistent with their beliefs. Different kinds of motivation can account for these effects. Scholars such as Kunda and Oleson (1995) and Yzerbyt et al. (1999) have argued that people may use pseudorelevant information to subtype deviant exemplars because they are motivated to adhere to their stereotypes. However, commercial interactions are not identical with the settings that have been studied in psychological research since they are usually characterized by some form of outcome dependency and economic exchange (Cowley 2005). Therefore, consumers may be more concerned about forming an accurate impression than about defending their prior beliefs. As such, the current studies demonstrate that the findings of previous research, although insightful, are not exactly paralleled in a brand-based, commercial context.

The findings reported here are also consistent with a theoretical model outlined by Kunda and Spencer (2003). These authors argue that one needs to consider the goals that people pursue in social interactions to understand if and to what extent they apply and update their stereotypic beliefs. Consistent with this reasoning, the current studies show that consumers may focus more strongly on pseudorelevant information and less strongly on the category because they may feel that doing so will help them in achieving a more successful outcome from the interaction.

Finally, the findings also contribute to research on the consequences of self-disclosures in customer-employee interactions. Whereas previous research has shown that selfdisclosures engender satisfaction and trust (Price and Arnould 1999), this study indicates that self-disclosures can also affect the extent to which consumers generalize an employee's behavior. This may entail positive as well as negative implications. On the one hand, the brand is not harmed as badly when the employee's behavior is inconsistent with the brand personality; on the other hand, the brand does not benefit as strongly when the behavior is consistent. Hence, more research may be needed to fully appreciate when selfdisclosures are beneficial or detrimental for a brand.

The issues addressed in this research also have several managerial implications. As such, this research may help managers in understanding when (and how) employees may help in strengthening the personalities of their brands. The studies indicate that managers need to pay close attention to interactions in which pseudorelevant information is not typically disclosed and which are characterized by a low degree of outcome dependency. For example, imagine that a consumer visits a bank like Citibank in order to complete such simple transactions as picking up account statements or cashing a check. Due to the straightforward nature of such transactions, the consumer would not be strongly dependent on one of the bank's tellers and is unlikely to receive any pseudorelevant information. As a result, the consumer is likely to generalize the employee's behavior to her existing impressions of Citibank. Consequently, managers at the bank need to ensure that their tellers understand what the personality of the bank stands for and may encourage them to confirm that personality through a set of standardized, "branded" behaviors.

Now imagine that the consumer visited the bank to complete a fairly complex transaction such as devising a new savings plan. In order to complete that transaction successfully, the customer would need to interact intensely with one of the bank's advisors. In this case, (s)he is more likely to receive pseudorelevant information and to subtype the advisor. Such interactions may exert less of an impact on consumers' brand personality impressions, even when the employee's behavior is consistent with their existing impressions. More generally, the results indicate that different interactions may contribute to brand equity in different veins. Whereas interactions in which pseudorelevant information is not typically disclosed may be useful for building strong brand personalities, interactions in which such information is typically disclosed may be more conducive to achieving such outcomes as trust and intimacy. Hence, managers may need to analyze the interactions taking place between their employees and their customers in order to determine through which processes employees may affect brand equity.

Although this research presents a set of findings that contribute to the literature focused on the formation of brand personality impressions, it also has some limitations that call for future research. One limitation concerns the fact that participants had to imagine the scenarios in the first two studies. While researchers studying similar issues have frequently used scenarios (e.g., Bitner 1990; Hess et al. 2003), one may argue that they are somewhat artificial. I 
attempted to achieve greater realism in Study 3 by using short films. However, future research may want to employ experimental manipulations that more closely resemble real-life experiences.

In a similar vein, the way in which accuracy motivation was manipulated in Study 3 may have been somewhat artificial. That is, it is hard to imagine a situation in which consumers are explicitly encouraged (or discouraged) to form an accurate impression of the employee they are interacting with. Note, however, that the purpose of Study 3 was to gain a more complete understanding of the cognitive processes that drive consumers to subtype an employee on the basis of pseudorelevant details. From this perspective, manipulating processing motivation through explicit instructions seemed advantageous. Notwithstanding, future studies may seek to manipulate accuracy motivation in a more realistic manner.

Finally, it was assumed that consumers are more concerned with forming an accurate impression of the employee rather than confirming their existing beliefs. In support of this reasoning, I have found that participants processed information that was consistent as well as inconsistent with their initial impressions in an unbiased fashion. However, there may be instances in which consumers may be more concerned with confirming their beliefs. That is, high levels of brand commitment may induce consumers to process consistent and inconsistent behaviors in a biased manner. Because committed consumers are motivated to confirm their positive impressions about the brand (Ahluwalia et al. 2000), they may subtype an employee whose behavior is inconsistent with the brand personality, even when they do not possess any pseudorelevant information. Conversely, they may ignore such information and generalize their experience when the employee's behavior is consistent. Manipulating brand commitment may therefore lead to a different pattern of results than the one observed in this research.

Acknowledgments This article is based on the author's dissertation completed at the University of St. Gallen. The author would like to thank his supervisor Torsten Tomczak for his continued support and encouragement. Furthermore, this article benefitted greatly from the comments of Martin Eisend, Valerie Folkes, Andreas Herrmann, Shashi Matta, Tom Meyvis, and the participants at the 2007 EMAC doctoral colloquium. Finally, the author would like to thank the editor and the four anonymous reviewers for their many helpful comments and suggestions.

\section{References}

Aaker, J. L. (1997). Dimensions of brand personality. JMR, Journal of Marketing Research, 34(August), 347-356. doi:10.2307/ 3151897.

Aaker, J. L., Fournier, S., \& Brasel, A. S. (2004). When good brands do bad. The Journal of Consumer Research, 31(June), 1-16. doi: $10.1086 / 383419$.
Aggarwal, P. (2004). The effects of brand relationship norms on consumer attitudes and behavior. The Journal of Consumer Research, 31(June), 87-101. doi:10.1086/383426.

Ahluwalia, R., Burnkrant, R. E., \& Rao Unnava, H. (2000). Consumer response to negative publicity: the moderating role of commitment. JMR, Journal of Marketing Research, 37(May), 203-214. doi:10.1509/jmkr.37.2.203.18734.

Altman, I., \& Taylor, D. A. (1973). Social Penetration: The Development of Interpersonal Relationships. New York: Holt, Rinehart, \& Winston.

Baron, R. M., \& Kenny, D. A. (1986). The moderator-mediator variable distinction in social psychological research: conceptual, strategic, and statistical considerations. Journal of Personality and Social Psychology, 51(6), 1173-1182. doi:10.1037/00223514.51.6.1173.

Bendapudi, N., \& Leone, R. P. (2003). Psychological implications of customer participation in co-production. Journal of Marketing, 67(January), 14-28. doi:10.1509/jmkg.67.1.14.18592.

Berry, L. L. (2000). Cultivating service brand equity. Journal of the Academy of Marketing Science, 28(1), 128-137. doi:10.1177/ 0092070300281012.

Bettencourt, L. A. (1997). Customer voluntary performance: customers as partners in service delivery. Journal of Retailing, 73(3), 383-406. doi:10.1016/S0022-4359(97)90024-5.

Bitner, M. J. (1990). Evaluating service encounters: the effects of physical surroundings and employee responses. Journal of Marketing, 54(April), 69-82. doi:10.2307/1251871.

Collins, N. L., \& Miller, L. C. (1994). Self-disclosure and liking: a meta-analytic review. Psychological Bulletin, 116(3), 457-475. doi:10.1037/0033-2909.116.3.457.

Cowley, E. (2005). Views from consumers next in line: the fundamental attribution error in a service setting. Journal of the Academy of Marketing Science, 33(2), 139-152. doi:10.1177/ 0092070304268627.

Crawford, M. T., Sherman, S. J., \& Hamilton, D. L. (2002). Perceived entitativity, stereotype formation, and the interchangeability of group members. Journal of Personality and Social Psychology, 83(5), 1076-1094.

Crosby, L. A., Evans, K. R., \& Cowles, D. (1990). Relationship quality in services selling: an interpersonal influence perspective. Journal of Marketing, 54(July), 68-81. doi:10.2307/1251817.

Fiske, S. T., \& Neuberg, S. L. (1990). A continuum model of impression formation from category-based to individuating processes. In M. Zanna (Ed.), Advances in Experimental Social Psychology, pp. 1-74. San Diego, CA: Academic.

Gilbert, D. T., \& Hixon, G. J. (1991). The trouble of thinking: activation and application of stereotypic beliefs. Journal of Personality and Social Psychology, 60(4), 509-517. doi:10.1037/0022-3514.60.4.509.

Grandey, A. A., Fisk, G. M., Mattila, A. S., Jansen, K. J., \& Sideman, L. A. (2005). Is service with a smile enough? Authenticity of positive displays during service encounters. Organizational Behavior and Human Decision Processes, 96, 38-55. doi:10.1016/j.obhdp. 2004.08.002.

Harré, R., \& Lamb, R. (1986). The Dictionary of Personality and Social Psychology. Oxford: Blackwell.

Hess, R. L,. Jr, Ganesan, S., \& Klein, N. M. (2003). Service failure and recovery: the impact of relationship factors on customer satisfaction. Journal of the Academy of Marketing Science, 31(2), 127-145. doi:10.1177/0092070302250898.

Hilton, J. L., \& Darley, J. M. (1991). The effects of interaction goals on person perception. In M. Zanna (Ed.), Advances in Experimental Social Psychology, pp. 236-267. Orlando, FL: Academic.

Hilton, J. L., \& Fein, S. (1989). The role of typical diagnosticity in stereotype-based judgments. Journal of Personality and Social Psychology, 57(2), 201-211. doi:10.1037/0022-3514.57.2.201. 
Johar, G. V., Sengupta, J., \& Aaker, J. L. (2005). Two roads to updating brand personality impressions: trait versus evaluative inferencing. JMR, Journal of Marketing Research, 42(November), 458-469. doi:10.1509/jmkr.2005.42.4.458.

Kardes, F. R. (1986). Effects of initial product judgments on subsequent memory-based judgments. The Journal of Consumer Research, 13(June), 1-11. doi:10.1086/209043.

Klein, O., \& Snyder, M. (2003). Stereotypes and behavioral confirmation: from interpersonal to intergroup perspectives. In M. Zanna (Ed.), Advances in Experimental Social Psychology, pp. 153-234. San Diego, CA: Academic.

Kunda, Z., \& Oleson, K. C. (1995). Maintaining stereotypes in the face of disconfirmation: constructing grounds for subtyping deviants. Journal of Personality and Social Psychology, 68(4), 565-579. doi:10.1037/0022-3514.68.4.565.

Kunda, Z., \& Spencer, S. J. (2003). When do stereotypes come to mind and when do they color judgment? a goal-based theoretical framework for stereotype activation and application. Psychological Bulletin, 129(4), 522-544. doi:10.1037/0033-2909.129.4.522.

Kunda, Z., \& Thagard, P. (1996). Forming impressions from stereotypes, traits, and behaviors: a parallel-constraint-satisfaction theory. Psychological Review, 103(2), 284-308. doi:10.1037/ 0033-295X.103.2.284.

Matta, S., \& Folkes, V. S. (2005). Inferences about the brand from counterstereotypical service providers. The Journal of Consumer Research, 32(September), 196-206. doi:10.1086/432229.

Neuberg, S. L., \& Fiske, S. T. (1987). Motivational influences on impression formation: outcome dependency, accuracy-driven attention, and individuating processes. Journal of Personality and Social Psychology, 53(3), 431-444. doi:10.1037/00223514.53.3.431.

Price, L. L., \& Arnould, E. J. (1999). Commercial friendships: service provider-client relationships in context. Journal of Marketing, 63 (October), 38-56. doi:10.2307/1251973.

Rothbart, M., \& Lewis, S. (1988). Inferring category attributes from exemplar attributes: geometric shapes and social categories. Journal of Personality and Social Psychology, 55(6), 861-872. doi:10.1037/0022-3514.55.6.861.

Ruscher, J. B., \& Fiske, S. T. (1990). Interpersonal competition can cause individuating processes. Journal of Personality and Social Psychology, 58(5), 832-843. doi:10.1037/0022-3514.58.5.832.

Sedikides, C., Campbell, W. K., Reeder, G. D., \& Elliott, A. J. (1998). The self-serving bias in relational context. Journal of Personality and Social Psychology, 74(2), 378-386. doi:10.1037/00223514.74.2.378.

Thompson, E. P., Roman, R. J., Moskowitz, G. B., Chaiken, S., \& Bargh, J. A. (1994). Accuracy motivation attenuates covert priming: the systematic reprocessing of social information. Journal of Personality and Social Psychology, 66(3), 474-489. doi:10.1037/0022-3514.66.3.474.

Yoon, C., Gutchess, A. H., Feinberg, F., \& Polk, T. A. (2006). A functional magnetic resonance imaging study of neural dissociations between brand and person judgments. The Journal of Consumer Research, 33(June), 31-40. doi:10.1086/504132.

Yzerbyt, V. Y., Coull, A., \& Rocher, S. J. (1999). Fencing off the deviant: the role of cognitive resources in the maintenance of stereotypes. Journal of Personality and Social Psychology, 77(3), 449-462. doi:10.1037/0022-3514.77.3.449. 